\title{
A strategic health initiative: context for Coronavirus
}

\author{
Richard Ennals ${ }^{1}$
}

Received: 20 March 2020 / Accepted: 23 March 2020 / Published online: 4 April 2020

(c) Springer-Verlag London Ltd., part of Springer Nature 2020

The current Coronavirus pandemic is a disruptive event, a global "Kodak Moment" (Johnsen et al 2018). Life will not be the same again. This does not mean that there had been no previous warnings. We now need to think about ways forward after the pandemic. Back in September 1985, at a conference in Brighton hosted by the AI\&Society Editor, Karamjit Gill, on "Artificial Intelligence for Society", we discussed ways forward in our field. I was working at Imperial College and in the UK Alvey Directorate, designing and managing research and development in Advanced IT. I outlined a suggested "Strategic Health Initiative", which was published in AI For Society (Ennals 1986b), and in Star Wars: A Question of Initiative (Ennals 1986a). Over the last 34 years, there have of course been many major technological advances. However, I suggest that the principles set out in the paper remain valid for the new context in March 2020.

The Strategic Health Initiative in 1986 argued for drawing on progress in medical science, advanced computing and social administration. It was then held that success would have enormous potential benefits, not only for the health of the nation, but also for the economy. Improved health and medical services would provide considerable financial benefits, as would the development of a better trained workforce. It would have direct effects on the whole population, bringing them into contact with computer technology in a benevolent context, reducing the division into two nations of "haves" and "have nots" with respect to health and computer literacy. The health of individuals is seen as integral to the health of the nation. Illness is not a crime to be punished by financial penalties, and information concerning the restoration of health should be freely available in accessible terms.

Reflecting back on the 1986 intiative, one significant area for the application of advanced technology was identified as the Health Service. At the time of its establishment in 1948, the National Health Service (NHS) was a model for

Richard Ennals

richard.ennals@gmail.com

1 Kingston University, Kingston Hill, Kingston KT2 7LB, UK international health care provision, and a central part of the policy of a government which was concerned to strengthen its people after suffering and war, seeing such provision as an essential investment. The NHS has since suffered from government neglect, with funding failing to match needs, and hospitals not being equipped with the same level of technology that should be standard in other advanced countries. It has become regarded all too often as an optional expense, increasingly to be devolved to the individual or the "community", where the financial resources required for work with advanced technology are not available. Even now in 2020, this health care deficit sounds familiar.

I argued then that prevention may be better than cure, but that the system of financial incentives is biased towards cure. In these dire times of the Coronavirus, I wonder what has changed. In 1986, I noted that where known enemy diseases threaten, our detection equipment is out of order. Straightforward tests were available for many forms of cancer, yet general scanning was not carried out on grounds of cost, and where intelligence of invasive disease had been acquired, all too often it was not transmitted to the individuals concerned. The computer systems capable of managing the information existed, but the funds were not provided to pay for them. We had the necessary technology for much of this work, but we lacked the political will to apply it. To quote Ian Lloyd MP, "We have found the enemy, and he is us". Our front line medical troops were pitifully resourced, and were made to work inordinate hours in the medical trenches with substandard weapons. Patients had to be turned away from hightechnology treatment in the cause of economy. Intensive care facilities were kept in mothballs. With changes in cleaning and catering arrangements, hospitals might not be healthy places to be if you were ill. Patients would rather not be ill, and, if ill, would rather not trouble the doctor. Civil defence advice is needed for patients in their homes, and in diagnosing the source of attacks of headache or nausea, preventive measures to enable them to take evasive action, getting out of the line of fire of heart disease, cancer or cirrhosis of the liver. "Protect and survive" should be the watchword for the citizen in the blasted wasteland of community medicine. 
Often we have the resources available to repel an attack from outside, but they are not sufficiently organised. Doctors need decision support as they seek to define a strategy with a particular patient and crisis management tools as numerous complaints emerge, or as competing demands are made for scarce resources. Increasingly they need a mastery of the official rules and regulations (on, e.g. the prescription of certain drugs and their generic substitutes) and an encyclopaedic knowledge of drugs and their interactions. They need to be able to explain their diagnoses and treatment in appropriate language, based on a model of the level of knowledge of patients and their families, and to draw on the experience of others. In the community medicine field, whether of barefoot doctors or a team of mobile professionals, information needs to be assembled, available and explicable. Advanced medical teamwork requires advanced information technology if the varied knowledge of the interdisciplinary team is to be brought to bear on shared problems.

Even in those early days of 1986, it was clear to me that with the advent of artificial intelligence techniques, further advances are made possible. Artificial intelligence is concerned with the study of human thinking, and its modelling in computer programs. We can learn about particular problems by attempting to model them, and the consequent programs can be of use in helping people to solve such problems themselves. Early work has been done in psychiatry and psychotherapy, and in problems of vision and speech, which shows the potential for further work. Military funding has gone into systems for voice and speech recognition, and for message understanding. An application focus in the field of intensive medical care or care of the multiply handicapped could be extremely beneficial, using, for example, speech-driven workstations as were developed on an Alvey large demonstrator project.

The Strategic Health Initiative of 1986 argued that if such a programme was successful, the strategic results for the country could be spectacular. We could expect an improvement in the health of the population, with a cost-effective change of emphasis to prevention rather than cure, and a fall in the number of working days lost each year through illness. The research community could benefit from the motivation of work in "advanced technology with a human face". Intelligent computer technology places a new burden on us to determine the kind of society in which we choose to live. It assumes the form laid down by its masters.

As in 1986, I still believe that researchers prefer to work on projects they believe in. Their brains cannot simply be hired for whatever purpose. Although in the age of machine learning and deep learning, AI scientists may be able to command astronomical salaries for being transferred between research centres like football stars, we still find skilled researchers who are dedicated to the development of socially responsive AI systems and tools for health and welfare of people. Their choice of where to work need not be determined by money: after years of neglect they are suddenly in a new position of power where they can refuse work which they find ethically unacceptable. They can choose instead to focus on fundamental research effort on attempting to solve human problems. In this spirit, we again suggest an initiative to tap this supply of idealism. We need a strategic focus for the next stage of development of an infant generation of technology, to the benefit of society in general: a Strategic Health Initiative.

If we abdicate from participation in the decisions as to how the technology is to be used, we must accept responsibility for what follows. I close with the words of Lord Beveridge, whose work laid the foundations of the British Welfare State, including the National Health Service.

"The object of the government in peace and in war is not the glory of rulers or of races, but the happiness of the common man.” Beveridge Report 1942

Curmudgeon Corner Curmudgeon Corner is a short opinionated column on trends in technology, arts, science and society, commenting on issues of concern to the research community and wider society. Whilst the drive for super-human intelligence promotes potential benefits to wider society, it also raises deep concerns of existential risk, thereby highlighting the need for an ongoing conversation between technology and society. At the core of Curmudgeon concern is the question: What is it to be human in the age of the AI machine? -Editor.

\section{References}

Beveridge W (1942) Beveridge report: social insurance and allied services. HMSO, London

Ennals R (1986a) A way forward for advanced information technology: SHI-a strategic health initiative. In: Star wars: a question of initiative. Wiley, Chichester, pp 122-135

Ennals R (1986b) A way forward for advanced information technology: SHI-a strategic health initiative. In: Gill KS (ed) Artificial intelligence for society. Wiley, Chichester, pp 19-30

Johnsen H et al (eds) (2018) Coping with the future: rethinking assumptions for society, business and work. Routledge, London

Publisher's Note Springer Nature remains neutral with regard to jurisdictional claims in published maps and institutional affiliations. 